\title{
КОНТИНЕНТАЛЬНОЕ ОБРАМЛЕНИЕ И ОКРАИННЫЕ МОРЯ ТИХОГО ОКЕАНА КАК ПЛАНЕТАРНАЯ ЛАНДШАФТНАЯ ГЕОСИСТЕМА В ОСВОЕНИИ МИРОВОГО ОКЕАНА
}

\author{
Старожилов В. Т., \\ Тихоокеанский международный ландшафтный иентр ШЕН ДВФУ, \\ Дальневосточный Федеральный университет. Владивосток. Россия
}

\begin{abstract}
Аннотация. Констатируется, что континентальное обрамление и окраинные моря Тихого океана как планетарная ландшафтная геосистема в освоении Мирового океана и выделенные как Тихоокеанский ландшафтный пояс (https://doi.org/10.18411/a-2017-089) как основа - модель научного и практического освоения геосистемы океан- континент ранее не рассматривалась. В настоящее время в связи с освоением переходной зоны Азиатского континента к океану появилась необходимость рассмотреть возможности применения ландшафтного подхода в практиках освоения геосистем этой зоны. Работа, представляет собой продолжение комплексных исследований в целом сформировавшейся ландшафтной школы профессора В.Т. Старожилова (doi:10.24411/1728-323X-2020-13079, doi:10.18411/lj-05-2020-26). Отмечается, что комплексное изучение ландшафтной структуры обрамления Тихого океана, имеет базовое значение при природопользовании Мирового океана. Именно ландшафтный пояс, включающий Сихотэ-Алинскую, Нижнеамурскую, Камчатско-Курильскую, Сахалинскую и другие ландшафтные области и сопряженные с ними окраинные моря, представляет собой часть единой с Тихим океаном структуры природы и представляются как основа для выполнения задач науки и практики освоения территорий континентального обрамления Тихого океана, окраинных морей и использования материалов в освоении Мирового океана. Он, как планетарная ландшафтная структура, является базовой моделью «фундаментом» для построения гармонизированных с природой и связанных с океаном экологических, сельскохозяйственных и других отраслевых моделей освоения этой обширной тихоокеанской зоны. Отмечается, что в свою очередь применение компьютерной технологии векторно-слоевого ландшафтного метода создают платформу для разработки планов и проектов освоения. Он также является платформой для обучения студентов. Приводятся данные о картографической обеспеченности пояса современными векторнослоевыми цифровыми материалами.
\end{abstract}

Ключевые слова: ландшафт, пояс, Тихоокеанский, освоение, океан.

\section{CONTINENTAL FRAMING AND OUTDOOR SEAS \\ THE PACIFIC OCEAN AS A PLANETARY LANDSCAPE GEOSYSTEM IN THE DEVELOPMENT OF THE WORLD OCEAN}

\author{
Starozhilov V.T. \\ Pacific International Landscape Center of the School of Natural Sciences, \\ Far Eastern Federal University. Vladivostok. Russia
}

\begin{abstract}
It is stated that the continental framing and marginal seas of the Pacific Ocean as a planetary landscape geosystem in the development of the World Ocean and identified as the Pacific landscape belt (https://doi.org/10.18411/a-2017-089) as a basis - a model of scientific and practical development of the geosystem ocean-continent has not been previously considered. Currently, in connection with the development of the transition zone of the Asian continent to the ocean, it is necessary to consider the possibilities of applying the landscape approach in the practice of developing the geosystems of this zone. The work is a continuation of the comprehensive studies of
\end{abstract}


the generally formed landscape school of Professor V.T. Starozhilov (doi: 10.24411 / 1728-323X2020-13079, doi: $10.18411 / \mathrm{lj}-05-2020-26)$. It is noted that a comprehensive study of the landscape structure of the Pacific Ocean framing is of fundamental importance in the use of natural resources in the World Ocean. It is the landscape belt, including the Sikhote-Alin, Nizhneamur, Kamchatka-Kuril, Sakhalin and other landscape areas and the marginal seas associated with them, that is a part of the structure of nature united with the Pacific Ocean and is presented as the basis for fulfilling the tasks of science and practice of developing territories of the continental framing The Pacific Ocean, marginal seas and the use of materials in the development of the World Ocean. It, as a planetary landscape structure, is the basic model "foundation" for building harmonized with nature and related to the ocean ecological, agricultural and other sectoral models for the development of this vast Pacific zone. It is noted that, in turn, the use of computer technology of the vector-layer landscape method creates a platform for the development of plans and development projects. It is also a platform for student learning. The data on the cartographic provision of the belt with modern vectorlayer digital materials are presented.

Key words: landscape, belt, Pacific, development, ocean.

\section{Введение.}

В последние десятилетия в Российской Федерации большое внимание уделяется вопросам освоения Востока России и Мирового океана. При этом рассматриваются задачи экологии территорий освоения и экологически чистого развития многоотраслевого природопользования на основе учета природы в виде ландшафтных документов как основы «фундамента» построения отраслевых краеведческих,экологических, сельскохозяйственных, биоресурсных, экономических, агропочвенных, строительных и других моделей [1]. Наблюдается тенденция применения ландшафтных моделей как основы планирования и управления освоения континентального обрамления и окраинных морей и участия таких моделей в построении моделей освоения Мирового океана и российской его части. Такие планомерные исследования стали возможными в связи с организацией профессором В.Т. Старожиловым в Дальневосточном федеральном университете по инициативе ректора ДВФУ и депутата Совета Федерации Тихоокеанского международного ландшафтного центра. На сегодняшний день в ДВФУ на Дальнем Востоке сложилась новая ландшафтная школа под руководством В.Т. Старожилова, которая способна решать практические задачи по освоению территорий Тихоокеанской России и развитию теоретической базы ландшафтной географии (doi:10.24411/1728-323X-2020-13079, doi:10.18411/1j-05-2020-26, https://www.dvfu.ru/expertise/news/science/landshaftnaya_shkola_professora_starozhilova/). B настоящее время в связи с освоением переходной зоны Азиатского континента к океану появилась необходимость рассмотреть возможности применения ландшафтного подхода в практиках освоения континентального обрамления и окраинных морей Тихого океана как планетарной геосистемы в освоении Мирового океана. Работа, представляет собой продолжение комплексных исследований Тихоокеанского международного ландшафтного центра ШЕН ДВФУ, работ по Тихоокеанскому ландшафтному поясу (doi:10.18411/a-2017089), (https://doi.org/10.18411/a-2017-089), а также разработанных парадигм: общей Дальневосточной ландшафтной парадигмы и Дальневосточной ландшафтной парадигмы индикации и планирования (doi:10.18411/1j-05-2020-26), разработок по картографическому оцифрованному ландшафтному обеспечению индикации, планирования и геоэкологического мониторинга юга Тихоокеанского ландшафтного пояса России (doi:10.18411/1j-05-2020-27), а также по «Ландшафтному звену выстраивания планирования и развития экономических, градостроительных и др. структур осваиваемых территорий» (doi: 10.18411/lj-09-2020-36).

На основе исследований обширной зоны континентального обрамления и сопряженных с ним окраинных морей на основе нового для России комплексного подхода в понимании зоны перехода континента к океану, основанном на 
междисциплинарном синтезе, анализе и оценке компонентов его внутреннего содержания (включает фундамент, рельеф, климат, почвы, растительность, биоценозы) $[1,3,4]$ и применения ландшафтной методологии изучения территорий, рассматриваемая в работе зона континентального обрамления и сопряженных с ним окраинных морей выделена в единную планетарную ландшафтную структуру Тихоокеанский ландшафтный пояс (https://doi.org/10.18411/a-2017-089). Он выделен на основе учета взаимодействия, взаимообусловленности и взаимопроникновения друг в друга компонентов, на основе изучения ландшафтов в условиях окраинно-континентальной дихотомии, на основе изучения орогенического, орографического, климатического и фиторастительного взаимодействующих между собой факторов. Комплексное изучение ландшафтного пояса как объемной ландшафтной (природной) структуры континентального обрамления Тихого океана, имеет (как структурная ландшафтная единица Земли) базовое значение при природопользовании зоны перехода от континента к океану и использовании этого материала для решения вопросов освоения Мирового океана. Именно ландшафтный пояс, включающий Сихотэ-Алинскую, Нижнеамурскую, Камчатско-Курильскую, Сахалинскую и другие ландшафтные области, как результат взаимодействующих орогенического, орографического, климатического и фиторастительного факторов, с природными границами, представляет собой барьерную структуру зоны перехода континента к океану, фокус взаимодействия континентальных и океанских ландшафтных структур, особым отражением экзогенных и эндогенных процессов и характеризующийся богатством природных ресурсов. Пояс представляет собой часть единой с Тихим океаном структуры природы и эта часть представляется как ландшафтная основа для выполнения задач науки и практики освоения территорий обрамления Тихого океана и окраинных морей и использования этих материалов при решении вопросов освоения Мирового океана.

Исследованиями установлено, что именно азональные пояса, представляют не достающее звено в комплексном изучении Мирового океана. Тихоокеанский ландшафтный пояс (зона перехода континента к океану) представляется конкретным базовым структурным элементом геосистемы континент-Мировой океан, объектом комплексной систематизации материалов, планирования, управления освоения окраинной континентальной и морской зоны Тихого океана. Однако, на сегодняшний день все еще отсутствуют плановые профессиональные исследования по практикам применения ландшафтных материалов по Тихоокеанскому ландшафтному поясу в планировании и управлении освоения геосистемы континент-Мировой океан. В целом это и определяет актуальность выполненной работы.

Цель публикации - обосновать в Российской науке необходимость на основе применения ландшафтного метода рассматривать континентальное обрамление и сопряженные с ним окраинные моря Тихого океана, выделенных как Тихоокеанский ландшафтный пояс, как равноценную природную структуру диалектической пары геосистемы континент-Мировой океан и обосновать её базовый комплексный характер и как ландшафтную основу-модель освоения зоны перехода и использование материалов при решении вопросов освоения системы континент-Мировой океан. Ландшафтную модель - пояс рассматривать природным «фундаментом» и основой для построения гармонизированных с континентальной природой и океаном научных и практик-моделей освоения (краеведческих, экологических, сельскохозяйственных, экономических, социальных, градостроительных и других).

\section{Материалы и методы.}

Общая методологическая основа исследования ландшафтный подход, в котором ландшафтному анализу подвергаются геосистемы различных рангов и в конечном итоге дается та или иная географическая оценка ландшафтного пространства объекта исследования, а полученные результаты анализа, синтеза и оценки применяются для решения задач комплексного освоения территорий. С методической точки зрения континентальное обрамление и сопряженные с ним окраинные моря (Тихоокеанских 
ландшафтный пояс) представляет собой часть единой с Тихим океаном структуру природы и представляется как основа для выполнения задач науки и практик освоения территорий континентального обрамления и окраинных морей Тихого океана и применении их при решении вопросов освоения Мирового океана.

Значимым является то, что в основу выделения ландшафтной основы-модели при освоении зоны перехода положены многолетние авторские полевые геологогеографические и географические научные и производственные исследования обширной территории окраинной зоны Востока России, которые в свою очередь включают полевые исследования Сихотэ-Алинской, Сахалинской, Камчатской, Анадырьской ландшафтных областей $[5,6,8,9]$. В целом отметим, что весь полученный полевой и научный материал по ландшафтной основе-модели анализировался на междисциплинарном уровне, осмысливался и формулировался и благодаря этому была определена целостность континентального обрамления и сопряженных с ним окраинных морей Тихого океана, выделенных как Тихоокеанский ландшафтный пояс, и как географической единицы и важность её для выполнения задач освоения обрамления и окраинных морей Тихого океана. При обосновании применения ландшафтного пояса как основы - модели при освоении окраинно-континентальной переходной зоны к океану использовались материалы практической реализации ландшафтного подхода с применением ландшафтной индикации в различных областях природопользования [2,7]. Особо отметим, что для определения ландшафтной целостности Тихоокеанского ландшафтного пояса, как структурной единицы Земли соизмеримой с фокусом максимального взаимодействия океана и Азиатского континента, применены материалы авторских палеогеографических исследований. Применены результаты геологических и палеогеографических реконструкций по установлению генезиса, состава и тектонической эволюции фундамента пояса. Применялась авторская концепция геодинамической эволюции зоны перехода Азиатского континента к океану.

Использовались материалы, полученные по итогам многочисленных экспедиций на Сахалине, Камчатке, Чукотке и других территориям Тихоокеанского ландшафтного пояса России и в частности новые векторно-слоевые картографические материалы по отдельным регионам зоны континентального обрамления (сихотэ-алинской, сахалинской и др. ландшафтным областям). При обосновании применения ландшафтного пояса как основы - модели при освоении окраинно-континентальной переходной зоны к океану использовались материалы практической реализации ландшафтного подхода с применением ландшафтной индикации в различных областях природопользования, материалы по организации и структурам ландшафтов и профилям через континентальное обрамление и сопряженных с ними окраинным морям, в которых отражено установленное нами внутреннее содержание ландшафтов территории пояса в системе ландшафт, вид, род, подкласс, класс, округ, провинция, область, пояс. Использовался материал по выделенным высотно-ландшафтным комплексам горных, островных, озерных геосистем, а также их водосборов.

Весь имеющийся материал анализировался на основе сопряженного анализа и синтеза межкомпонентных и межландшафтных связей с учетом окраинноконтинентальной дихотомии и данных по орогеническому, орографическому, климатическому и фиторастительному факторам формирования географически единых территорий. Получены были следующие результаты.

Результаты и обсуждение.

При познании, формулировании возможностей и необходимости применения материалов по континентальному обрамлению и окраинным морям Тихого океана как планетарной ландшафтной геосистемы в освоении Мирового океана получен фундаментальный результат настоящих исследований, заключающийся в том, что для реализации рассмотрения возможностей и необходимости применения материалов по континентальному обрамлению и окраинным морям Тихого океана как планетарной 
ландшафтной геосистемы в освоении Мирового океана необходимо иметь прежде всего оцифрованную векторно-слоевую морфологическую ландшафтную основу [1]. Такие основы как в целом по поясу, так и по его отдельным регионам получены (Сихотэалинской, Сахалинской ландшафтным областям и др.). Для реализации поставленных задач получены, прежде всего, оцифрованные векторно-слоевые морфологические ландшафтные модели (векторно-слоевые ландшафтные карты), которые на цифровом уровне дают знание строения географического пространства рассматриваемого объекта. Этот результат позволяет проанализировать территории по оцифрованным выделам ландшафтов. Сравнить внутреннее содержание таких таксонов как ландшафт, вид, род, подкласс, класс, тип, округ, провинция, область, пояс. Затем решать задачи по практикам природопользования. Тем более, что результат включает современное компьютерное программное обеспечение.

Синтез, анализ обеспеченности континентального обрамления Тихого океана современными векторно-слоевыми картографическими материалами, составленными на основе современных требований картографии и математического обеспечения показывает следующую общую картину такой обеспеченности. Составлены карты и объяснительные записки к ним:

Карта ландшафтов Тихоокеанского ландшафтного пояса, областей и прилегающих морей в масштабе 1: 3000000 (автор Старожилов В.Т.). На карте также выделены ландшафтные области: Сихотэ-алинская, Нижнеамурская, Приохотская, Колымская, Анадырьская, Чукотская, Корякская, Камчатская, Сахалинская. Представлены сопряженные с областями окраинные моря исследования.

Ландшафтная карта Приморского края масштаба 1:1 000000 (автор Старожилов В.Т., сжатая версия электронной карты ландшафтов Приморского края масштаба 1:500 000);

Карта ландшафтного районирования Приморского края масштаба 1:1 000000 (автор Старожилов В.Т.). Выделено 54 округа, 8 провинций, 4 области;

На основе базовой карты ландшафтов Приморского края (на карте картографировано 3156 выделов ландшафтов), так как она цифровая, то было получено отдельных 3156 карт по всем выделенным на карте выделам ландшафтов. На основе карты районирования, так как она цифровая векторно-слоевая, то было получено отдельных 66 карт ландшафтных единиц районирования;

Впервые для АТР издана (автор Старожилов В.Т.) объяснительная записка к карте ландшафтов Приморского края масштаба 1: 500 000. В ней описано 3156 выделов ландшафтов;

На основе основной векторно-слоевой карты ландшафтов Приморского края составлены частные векторно-слоевые карты ландшафтов и высотно-ландшафтных комплексов островных, озерных и горных водосборов Тихоокеанского ландшафтного пояса, в том числе составлена карта ландшафтов и высотно-ландшафтных комплексов водосбора озера Ханка;

Ландшафтная карта острова Сахалин в масштабе 1 : 500 000. В настоящее время карта и объяснительная записка к ней готовятся к изданию;

Ландшафтная карта урочищ и групп урочищ о. Русский и прилегающих к нему островов Владивостокского городского округа масштаба 1: 25 000;

Карта положения и эволюции палеоструктур и сопряженных с ними элементов зоны перехода северо-востока Азии к Тихоокеанской плите.

Карты представляются значимым академическим творением в сфере цифровых карт, основанном на огромном опыте изысканий в области теории, а также практике ландшафтоведения, и вплоть до этих пор в части обзорности и содержательности не имеет аналогов для территории Азиатско - Тихоокеанского региона (АТР), охватывая Азиатские государства. Карты принадлежат к картам новейшего поколения, в которых в перспективе станут отображать в цифровом виде не отраслевые слои компонентов, но слои 
классификационных единиц ландшафтов. Немаловажно в таком случае то, что карты нацелены на практическую реализацию ландшафтного подхода в освоении земель, а также способны быть применены как естественные модели «фундамент» с целью формирования гармонизованных с природой экологических, гидрологических, экономических, социальных и др. моделей освоения территорий.

Также установлено, что получен фундаментальный результат по ландшафтам континентального обрамления Тихого океана в системе ландшафт, вид, род, класс, тип, округ, провинция, область, пояс, который нужно использовать в решении вопросов освоения Мирового океана.

\section{Заключение.}

Итак на Дальнем Востоке, в России под руководством профессора В.Т. Старожилова территория обрамления и окраинных морей Тихого океана выделяется как географически целостный Тихоокеанский ландшафтный пояс и как основа - модель научного и практического освоения геосистемы океан-континент, которая способна решать практические задачи по освоению территорий обрамления и окраинных морей Тихого океана и задачи освоения Мирового океана. Это сделано с использованием цифровых компьютерных технологий. В свою очередь применение компьютерной технологии векторно-слоевого ландшафтного метода создают платформу для разработки планов и проектов освоения. Она также является платформой для обучения студентов. Современное географическое понимание пояса как основы-модели его освоения выводит образование, науку и практику на новый информационный и прикладной уровни и позволит его рассматривать как эффективную ландшафтную модель «фундамент» для построения гармонизированных с ней сельскохозяйственных, краеведческих, гидрологических, экономических, социальных, экологических и других моделей геосистем. В целом необходимо выстроить новую схему научного и прикладного планирования и управления освоения геосистемы океан-континент и решение вопросов освоения Мирового океана. Именно азональные пояса, такие как Тихоокеанский ландшафтный пояс, представляют не достающее звено в комплексном изучении Мирового океана. Он представляется конкретным базовым структурным элементом геосистемы океан-континент, объектом комплексной систематизации материалов, планирования, управления освоения как окраинной континентальной и морской зоны Тихого океана. Пояс представляет собой равноценную часть диалектической пары океан-континент и такая его роль в геосистеме определяет высокую его значимость при освоении Мирового океана.

\section{Список литературы.}

1. Старожилов В.Т. Природопользование: практическая ландшафтная география. / учебник. Школа естественных наук ДВФУ, Тихоокеанского международного ландшафтного центра, Школа естественных наук ДВФУ. Владивосток, 2018. 276с

2. Старожилов В.Т. Эколого-ландшафтный подход в формировании региональной экологической политики на территории стран АТЭС / В сборнике: Шестые Гродековские чтения. Актуальные проблемы исследования Российской цивилизации на Дальнем Востоке. межрегиональная научно-практическая конференция. Правительство Хабаровского края. Хабаровск, 2009. С. 24-28.

3. Старожилов В.T. Региональные компоненты и факторы структуры и пространственной организации ландшафтов юга Дальнего Востока (на примере Приморского края). - Владивосток, 2007.

4. Старожилов В.Т. Ландшафтное картографирование территорий Приморского края // Известия Российской академии наук. Серия географическая. -2010. -№ 2. -С. 82-89.

5. Старожилов В.Т., Зонов Ю.Б. Ландшафтные предпосылки устойчивого развития территорий. / В сборнике: Природа без границ. Материалы I Международного экономического форума. Администрация Приморского края. 2006. С. 261-265. 
6. Старожилов В.Т. Ландшафтное районирование Приморского края. Вестник Дальневосточного отделения Российской академии наук. 2010. № 3 (151). С. 107-112.

7. Старожилов В.Т. Эколого-ландшафтный подход к промышленным территориям юга Дальнего Востока // В сборнике: Современные геофизические и географические исследования на Дальнем Востоке России. материалы 9-й научной конференции, Владивосток: конференция приурочена к Всемирным дням воды и метеорологии, а также к 110-летию ДВГУ и 45-летию ГФФ. Дальневосточный государственный университет, Институт окружающей среды; под редакцией Н. В. Шестакова. Владивосток, 2010. С. 155158.

8. Старожилов В.Т. Проблемы ресурсопользования, структура и пространственная организация ландшафтов приокеанских Дальневосточных территорий // В сборнике: Науки о Земле и отечественное образование: история и современность. материалы Всероссийской научно-практической конференции, посвященной памяти академика РАО А. В. Даринского. Российский государственный педагогический университет им. А. И. Герцена, факультет географии. 2007. С. 310-312.

9. Старожилов В. Т. Ландшафтные геосистемы Сахалинского звена Тихоокеанской России // В сборнике: Научная дискуссия: гуманитарные, естественные науки и технический прогресс. Материалы VII Всероссийской научно-практической конференции. 2015. C. 54-64. 